\title{
APRESENTAÇÃO DO DOSSIÊ: FEMINISMOS, POLÍTICA E LUTAS CONTEMPORÂNEAS DAS MULHERES
}

\section{DOSSIER PRESENTATION: FEMINISMS, POLITICS AND \\ CONTEMPORARY WOMEN'S FIGHTS}

Maria Mary Ferreira ${ }^{1}$

O debate feminista, que se instaurou no Brasil pós-impeachment de Dilma Rousseff, reacendeu as discussões sobre as diversas correntes desse movimento, discutidos em grande parte dos artigos deste Dossiê. Há clareza que não se pode falar mais de feminismo no singular, haja vista a pluralidade deste movimento que vem penetrando em várias esferas, atingindo públicos os mais diversos. Por essa razão, pode-se afirmar que o feminismo se renovou, ampliou e diversificou. Mas, não se pode deixar de considerar que cada feminismo retrata um contexto, uma época, um estado de espírito, uma maneira de resistir às diversas formas de opressão que as mulheres enfrentam ao longo dos Séculos.

Desse modo, não se pode desconsiderar as lutas feministas que na clandestinidade, nos anos sessenta e setenta, nos bastidores dos partidos e sindicatos, lutaram para romper a invisibilidade das mulheres em várias instâncias onde estavam e continuavam subrepresentadas. Como não rememorar a luta de Elizabeth Lobo dentro da CUT para retirar as mulheres do anonimato? Seu livro A Classe operária tem dois sexos, desnuda a presença e luta das mulheres operárias dentro dos sindicatos. Para a autora:

[...] A divisão do trabalho entre os sexos está na base da opressão da mulher na sociedade e na família e, para compreendê-la, é necessário combinar a análise do cotidiano da fábrica e do sindicato com a da família operária. É a partir desse cotidiano visível e invisível, na fábrica e em casa que se pode começar a discutir a autonomia das práticas sociais dos homens e das

\footnotetext{
${ }^{1}$ Professora Associada do Departamento de Biblioteconomia e do Programa de Pós Graduação em Políticas Públicas da Universidade Federal do Maranhão; Doutora em Sociologia pela UNESP/FCLAr. Atualmente faz Pós-Doutorado na Universidade do Porto/Portugal com bolsa da Fundação de Amparo à Pesquisa e ao Desenvolvimento Científico e Tecnológico do Maranhão (FAPEMA)
} 


\section{Revista (1) ( \\ Debates Insubmissos}

mulheres dentro da classe operária e sua integração nas lutas do movimento operário no Brasil. (SOUZA-LOBO, 1991, p. 42).

Como esquecer a luta de Margarida Alves, no sertão da Paraíba, combatendo com as mulheres rurais o latifúndio. Como esquecer de Silvia Cantanhede que, juntamente com várias mulheres negras maranhenses, cria no início dos anos oitenta um dos primeiros grupos de feministas negras do Brasil, o Mãe Andresa, em homenagem a uma mãe de terreiro maranhense. Como não lembrar e rememorar as intervenções de Ana Alice Alcântara Costa que, desde os anos setenta, contribuiu para transformar a Bahia em um Estado composto por um feminismo vibrante, mostrando ao Brasil que no nordeste brasileiro havia resistência, havia feminismo, não era um movimento que se concentrava somente no eixo Rio-São Paulo.

O feminismo no Brasil, desde sua emergência em tempos da ditadura, irradiou em todo o país, demonstrando o descontentamento das mulheres contra a opressão patriarcal, desnudando as desigualdades salarias, denunciando os crimes da "paixão", trazendo a insatisfação das feministas negras contra a hegemonia das feministas brancas, suscitando as denúncias das lésbicas contra a sexualidade normativa que durante séculos as excluiu e ainda exclui. São muitas experiências feministas que demonstram a diversidade deste movimento rechaçado pela direita, condenado pelos fundamentalistas, criticado pelas esquerdas. Sobrevivemos! Os exemplos são apresentados neste dossiê o qual traz um conjunto de reflexão que ajuda a pensar a pluralidade do feminismo e, neste contexto, apresenta-se enquanto forma agregadora de luta.

No texto que abre o dossiê de minha autoria sobre Movimentos feministas no Brasil e sua ação insubmissa frente ao golpe de 2016 ressalto a ação das feministas, em diferentes frentes, para denunciar aquilo que para todas nós sempre foi óbvio: o impeachment foi um golpe orquestrado contra os brasileiros e brasileiras a fim de garantir ao capital estrangeiro a apropriação das nossas riquezas, em especial o pré-sal, aumentar os ganhos da elite através de leis e reformas que destruíram o mínimo de conquistas adquiridas na última década.

É uma luta que vem de longe, como destaco no meu texto, luta em que muitas barreiras tiveram que ser ultrapassadas, muitos esforços foram registrados para que, de forma gradativa, nós mulheres pudéssemos superar as relações opressores em que se vivia e que muitas ainda vivem. Foram esses esforços que nos levaram a condição de sujeito. Os passos 
se mostraram lentos, cobertos de pequenas vitórias através das quais era possível transgredir. As pioneiras da primeira onda do feminismo no Brasil estão saindo do anonimato, para clarificar que nós mulheres não aceitamos passivas os destinos determinados pela sociedade patriarcal de então. O texto de Simone Maria dos Santos e Nayara Aparecida de Moura traz para o cenário acadêmico O Feminismo de Primeira Onda no Interior de Minas Gerais Pelas Mãos de Maria de Lourdes Teixeira que escreveu regularmente entre os anos de 1922 e 1923 para o Jornal A Estrella da Oeste. As crônicas de Lourdes Teixeira, muitas delas escrita sob pseudônimo, denunciava a opressão da mulher, defendia o direito das mulheres à educação e foi uma das pioneiras na defesa do divórcio, por considerar que muitas mulheres sofriam caladas os casamentos infelizes, no qual ela chama de "a dor sem remédio de um mal sem cura".

A diversidade dos feminismos possibilitou a abertura de diversas frentes e demandas que trazem diferentes leituras da realidade das mulheres, dado a suas vivências, condição social, interesses, dores e sofrimentos. As mulheres do Conjunto de Favelas da Maré, como bem enfatiza Patrícia Rivera (2018) evidenciam uma forma de vivenciar o feminismo decolonial e pós-colonial articulado pelas mulheres, principalmente negras, que resistem à segregação e constroem, de forma criativa, convivências voltadas à igualdade de gênero no contexto da periferia, onde a luta de classe e a luta pela a igualdade de gênero e étnico racial se articulam intersetorialmente no combate à violência de gênero, principalmente. Nestas experiências de feminismo destacam-se as pedagogias que lembram os feminismos que eclodiram nos anos sessenta e setenta, cujas práticas se aproximam.

A violência contra as mulheres perpassa as questões de classe, de raça e etnia, embora saibamos que são as mulheres negras as maiores vítimas como bem evidencia os estudos pioneiros de Helleieth Saffiotti entre os quais destaco $O$ poder do macho. Este poder nunca esteve tão forte e evidente como no processo do impeachment, nas cenas que agrediram todas as mulheres, dada a misoginia com que foi explicitada. As cenas registradas no processo de cassação do mandato de Dilma Rousseff não são cenas inéditas no cenário do Congresso Nacional, conforme nos descreve Juliene Tenório de Albuquerque e Elba Ravane Alves no texto revelador Apontamentos sobre a Violência contra a Mulher na Politica Institucional Brasileira. As autoras demonstram como a violência contra as mulheres, no campo político, é 
uma das formas de expressão da dominação masculina e se constitui enquanto variável que contribui para a baixa presença das mulheres nos espaços políticos. As agressões sofridas pelas deputadas Maria do Rosário, Jandira Feghali, entre outras, denotam o descaso do Estado para com a integridade das mulheres e se constitui um dos mecanismos de intimidação do exercício político das mulheres. A pouca atenção dada às agressões sofridas por aquelas mulheres evidencia a atualidade do patriarcado e sua difícil erradicação.

Para fechar o dossiê destacamos o texto de A paixão pela desigualdade, a interseccionalidade e os 'novos feminismos' de autoria de Lemuel Dourado Guerra Sobrinho e Lorene Dias Ferreira no qual analisam novas expressões dos feminismos: veganas, vegetarianas, feminismos negro à luz da visão de Rancière sobre democracia. A abordagem dos autores agrega pautas e discussões sobre a interseccionalidade e, deste modo, agregam a luta antirracista considerada central entre as feministas negras e as questões relacionadas ao especismo - entendido como a discriminação praticada pelos seres humanos em relação às outras espécies. Em suas reflexões, os autores revelam eventuais pontos de tensão a partir da conceituação da democracia e da política feita pelo autor mencionado. Os questionamentos apresentados no texto, ajudam a pensar o contexto de democracia em que se vive. A noção rancièriana de política contribui para delinear uma nova perspectiva sobre a seguinte questão: se os esforços atuais para produzir arranjos sociais mais democráticos em termos de gênero raça, classe e espécie se fundamentam na afirmação da desigualdade, como se pode esperar a subversão da ordem das desigualdades?

Para os autores, abraçar a "opinião da igualdade" requer o questionamento dessa maneira de pensar, ao mesmo tempo em que se reconhecem os limites desse questionamento, já que as comparações continuamente moldam - e são moldadas - pela linguagem da qual não se pode escapar em seu potencial de mediação de nossas experiências do mundo.

Os textos são importantes para refletir sobre esse momento do Pós Golpe, desse momento pré-eleitoral, em que aqueles que votaram pelo impeachment da Presidenta Dilma mudam seus discursos na campanha para conquistar votos, momento em que as mulheres que disputam cargos eletivos são hostilizadas e momento em que se ruir os discursos de democracia decantados no circo armado para construir o golpe. 
Os feminismos e as feministas em todo o processo do impeachment e do pós golpe desafiaram o patriarcado, os machismos, os racismos, a cultura do estupro, a subrepresentação. Suas falas expressas nos textos deste dossiê demonstram a contribuição da academia para pensar a sociedade a partir do olhar das mulheres e homens que consideram e fazem dos feminismos um movimento de resistência, contra a inferiorização das mulheres e contra todas as formas de opressão.

\section{REFERENCIAS}

SAFFIOTI, Heleieth I. B. O poder do macho. São Paulo: Moderna, 1987. 134 p.

SOUZA-LOBO, Elizabeth. A classe operária tem dois sexos: trabalho, dominação e resistência. São Paulo: Brasiliense, 1991.285p. 